\title{
When politics and the law determine psychiatric practice
}

Previously published at www.cmaj.ca

Danger to Self: On the Front Line with an ER Psychiatrist

Paul R. Linde

University of California Press; 2010.

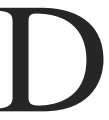
r. Paul Linde, an attending physician with the psychiatric emergency services at San Francisco General Hospital, California, senses sometimes that his work is derided by colleagues in other, more "glamorous" branches of medicine as "meatball... or veterinary psychiatry" and not given the respect it deserves. In this book, which chronicles some of his professional experiences and highlights a number of ethical and moral dilemmas he has had to wrestle with during his career, he defends his professional choice, noting that the work he and his coworkers do "is deeply rooted in respect for the patient. Most of us want to help people who have been left behind and forgotten by society."

More than half of the patients he sees come to him involuntarily, having been detained under civil code because of concerns that they are a danger to self or others, or gravely disabled by psychiatric illness. And so, despite trying to do the best he possibly can for his patients, including the difficult choices he faces in trying to decide whether to discharge or to hospitalize them, "many of whom feel, often justifiably, that they are treated as miscreants when their only 'crime' is of suffering symptoms of mental illness," he asks whether perhaps "libertarian psychiatrist Thomas Szasz was right, and we psychiatrists are, on our common Kafkaesque paths, now merely tools of society, agents of behavioral and social control."

Indeed, one of the recurring themes in this book, is the parallel between the way our society treats people with psychiatric illness and those who have committed crimes. Fully half of the chapters have titles that could have come out of a police procedural, including "the jailer," "the jury," "the speed cop" and "the judge."

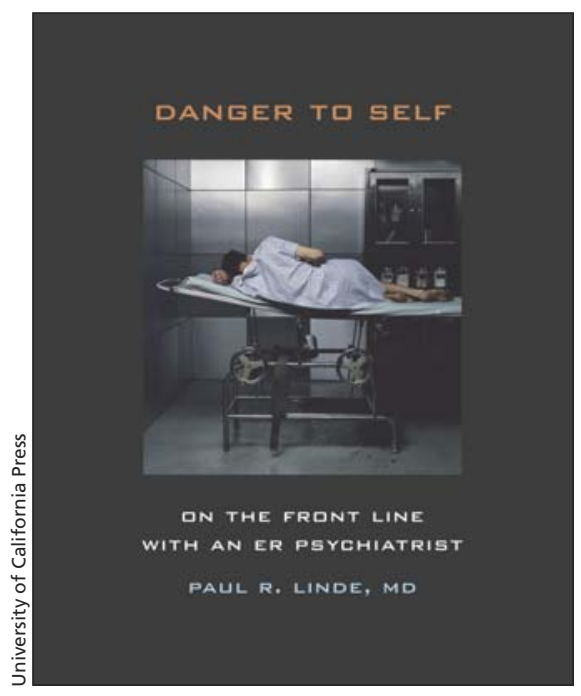

Linde points out that the environment in which he practises has not gotten more hospitable since he first started out; in fact, as he persuasively argues, the opposite is true. He notes that in 1958, 37500 patients were hospitalized in 10 state institutions across California, whereas 30 years later there were only 6000 inpatients in four state hospitals, with another estimated 20000-30000 psychiatric patients wandering the streets homeless. Though his institution is licensed by the state to hold up to 18 patients for a maximum of 24 hours, it often holds many more for two to three days at a time. "What else can we do with psychiatrically unstable patients... who have no place else to go?"

His frustration is not limited to the public health system, it extends to private insurance companies as well, which, by creating ever more regulations, rules, obstacles and paperwork "spend more money denying care than they do providing [it]." A number of legal decisions have also made it more difficult for him to care for patients, and he cites as examples Riese v. St. Mary's, which made it easier for patients to refuse psychiatric treatment, and other cases which suggest that psychiatrists should be able to predict the actions of people whose actions could pose a danger to themselves and others, something he refers to as the "crystal ball standard."

Linde decries "the unfortunate fact that changes in psychiatric practice over the years have been driven more by political, legal and regulatory factors than by any particular advances in scientific evidence." Whether to forcibly hospitalize a patient after an attempted suicide, and in doing so compromise his or her civil liberties, or to instead discharge the patient into an outpatient program in the belief (and hope) that another, this time successful, attempt is in the offing is an agonizing decision which, in the absence of the proverbial "crystal ball" can sometimes go horribly wrong.

This is brought home in a deeply moving chapter devoted to the story of a young man Linde sees following a suicide attempt. Linde decided to release the man into the care of his family only to have him succeed in hanging himself three days later. He tells the man's father that "in retrospect, I wish I had made a different decision... I wish I would have put him in the hospital, but I can't go back in time. I used my best judgment at the time. I'm sorry." Linde's own psychiatrist tells him afterwards that "that was a profoundly decent thing to do," though Linde, not able to fully let go of his remorse and feelings of guilt, notes that "sometimes decency is all anyone has to offer to a grieving person. Yes, I could give myself credit for that. But one cannot undo what has been done."

Danger to Self is an engaging and well-written book that comes across as genuine and heartfelt. Linde's purpose in writing it, it seemed to me, was two-fold: to present what he does to a wider audience in an interesting manner and to make readers aware of some of the difficulties that he and his colleagues face in doing their job on a daily basis. In both of these, Linde has succeeded admirably.

\section{Dennis Rosen MD}

Division of Respiratory Diseases Children's Hospital Boston

Harvard Medical School

Boston, USA 